Historic, Archive Document

Do not assume content reflects current scientific knowledge, policies, or practices. 


\section{WHOLESALE PRICE LIST GLADIOLUS BULBS 1922-1923}

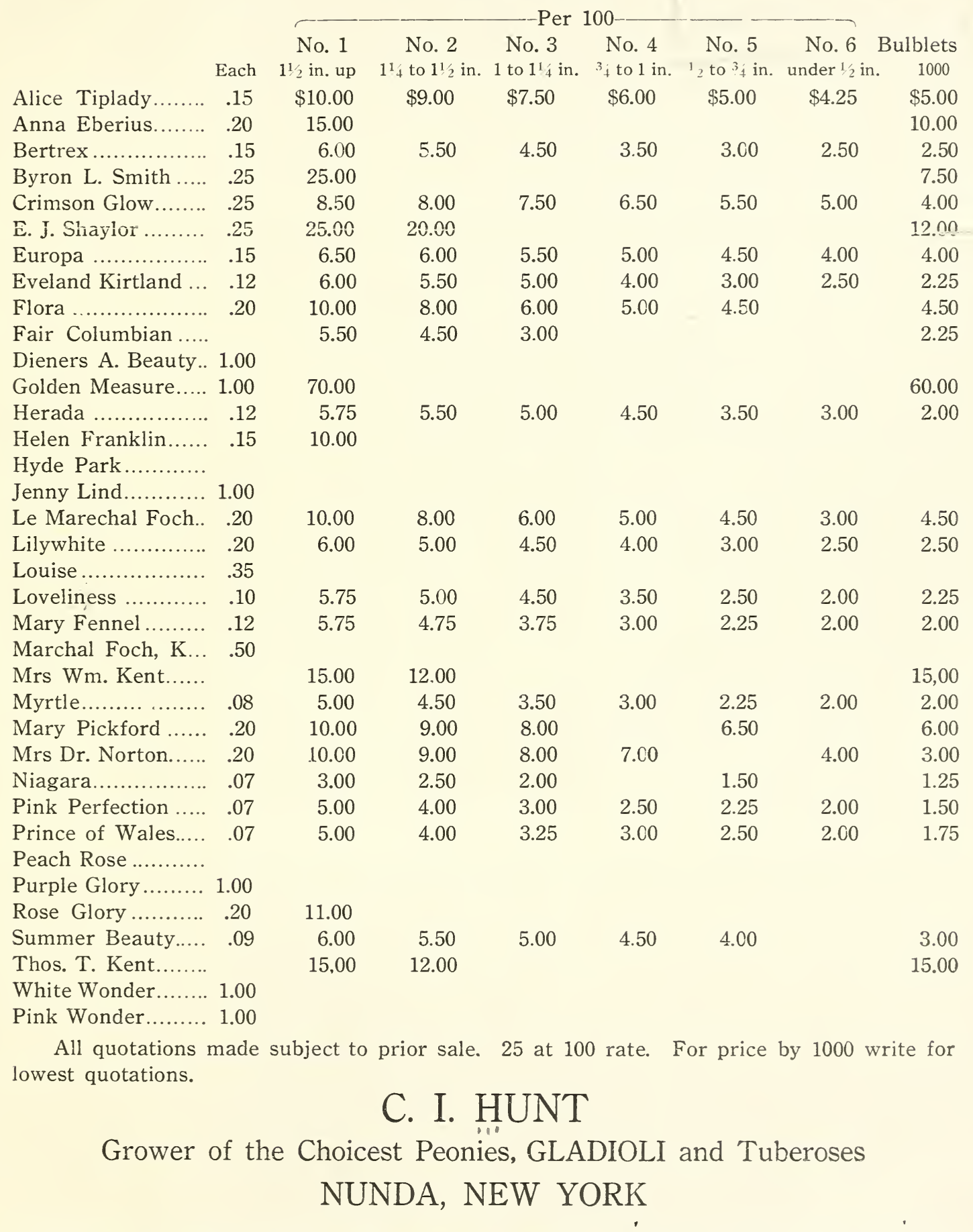

“The pessimist puts 2 and 2 together and gets 4 , but the opt mist gets 22 ." Be an optomist. 



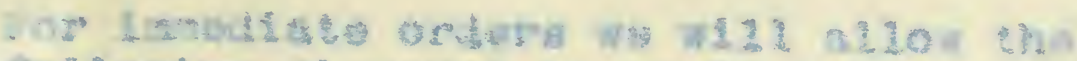

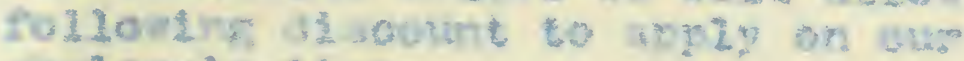
risolario 11 is.

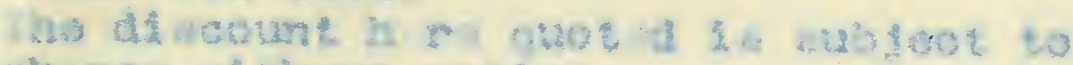
dh Lngo atehote motide.

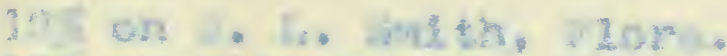

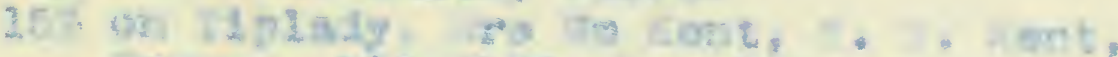

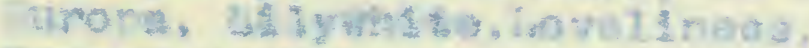
Butaer jeatey?

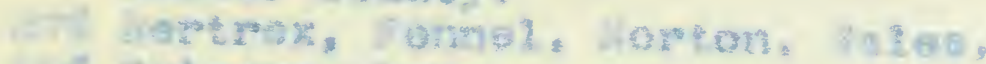

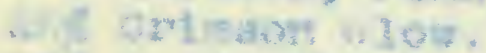

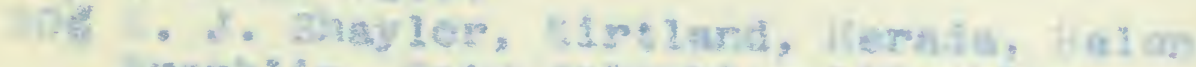

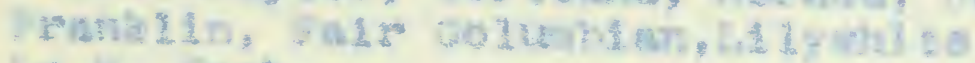
Lut II. voekt

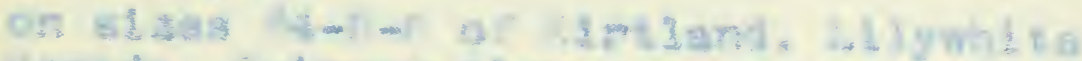

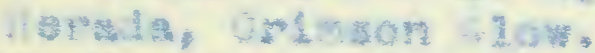

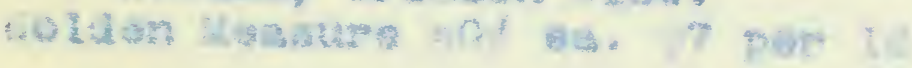

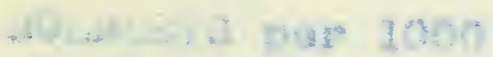

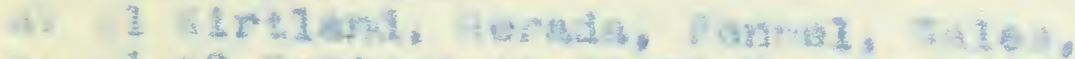

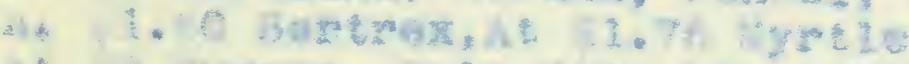

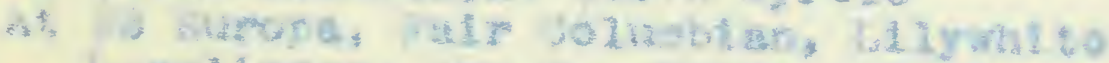

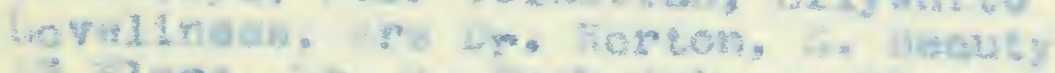

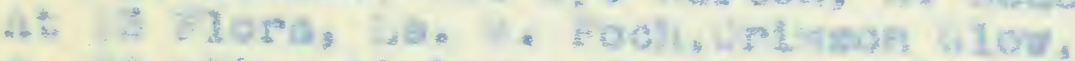

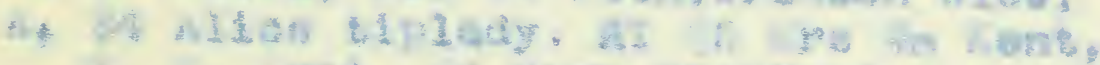

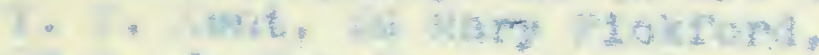

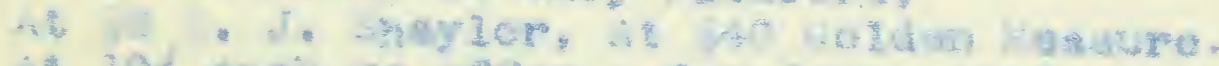

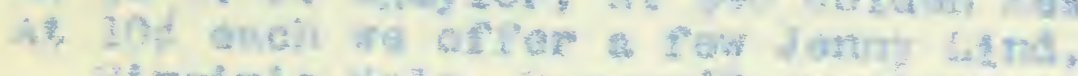

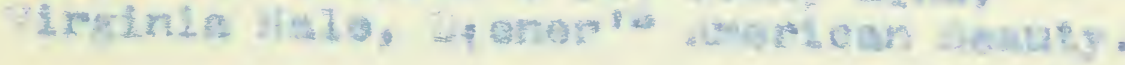

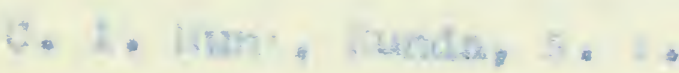


